\title{
Detection of Subpubic Tumor Causing Bladder Outlet Obstruction by 3D Perineal Ultrasound
}

\author{
Diagnose eines subpubischen Tumors bei einer Patientin \\ mit Blasenentleerungsstörung mittels 3-D-Perineal-Ultraschall
}

Authors

Affiliation
S. Albrich, J. Steetskamp, K. Rommens, S. Porta, M. Battista, G. Hoffmann, C. Skala

Department of Obstetrics and Gynecology, Johannes-Gutenberg-University Mainz, Mainz

Key words
sonography
@ dysuria
urinary incontinence
benign vaginal tumor
gynecology
Schlüsselwörter
Ultraschall
Dysurie
- Harninkontinenz
benigne Vaginatumoren
- Gynäkologie

received $\quad 30.4 .2015$

revised $\quad 3.6 .2015$

accepted 12.6.2015

Bibliography

Dol http://dx.doi.org/ 10.1055/s-0035-1546219

Geburtsh Frauenheilk 2015; 75: 719-722 @ Georg Thieme

Verlag KG Stuttgart · New York . ISSN 0016-5751

\section{Correspondence}

\section{Dr. Stefan Bernt Albrich}

Johannes-Gutenberg-University

Mainz

Department of Obstetrics

and Gynecology

Langenbeckstraße 1

55131 Mainz

albrich@uni-mainz.de

\section{Abstract \\ $\nabla$}

This case report shows that 3D perineal ultrasound can be superior to clinical examination and routine 2D perineal ultrasound in the detection of an unusual subpubic tumor. A 73-year-old female patient was referred to our urogynecological outpatient unit complaining of over-active bladder symptoms and voiding dysfunction for 3 years. Gynecological examination found no signs of pelvic organ prolapse or abnormality in the vaginal cavity. Routine 2D perineal ultrasound showed substantial residual urine (ca. $300 \mathrm{ml}$ on catheter) and limited bladder neck mobility, but no signs of pelvic organ prolapse. Use of standardized 3D perineal ultrasound revealed a $24 \times 26 \times$ $32 \mathrm{~mm}$ spherical, hypoechoic tumor below the pubic symphysis between the distal urethra and the pubic bones. This structure was mistaken for the pubic symphysis in the midline on 2D ultrasound performed earlier. At surgery, the tumor was completely excised through a vaginal incision between the urethra and the pubic symphysis. After an uneventful postoperative recovery the patient developed de-novo stress urinary incontinence, which was corrected successfully by the insertion of a retropubic tension-free suburethral sling after an interval of 8 weeks. After a further follow-up of 8 weeks the patient reported wellbeing, urinary continence and no voiding dysfunction; no abnormalities were found on examination. In conclusion, 3D perineal ultrasound is a useful additional tool for the diagnostic workup of bladder outlet obstruction.

\section{Zusammenfassung \\ $\nabla$}

In diesem Fallbericht beschreiben wir die Überlegenheit des 3-D-Perineal-Ultraschalls bei der Diagnose eines seltenen subpubischen Tumors. Eine 73-jährige Patientin wurde aufgrund von Harndrangbeschwerden und Blasenentleerungsstörungen seit 3 Jahren in unsere urogynäkologische Ambulanz überwiesen. Der gynäkologische Untersuchungsbefund zeigte keinen Anhalt für eine Genitalsenkung oder andere vaginale Auffälligkeiten. Im konventionellen 2-D-Perineal-Ultraschall fand sich deutlich Restharn (mittels Katheter objektiviert $300 \mathrm{ml}$ ), eine geringe Blasenhals-Mobilität und ebenfalls keine wesentliche Senkung. Durch die Hinzunahme des standardisierten 3-DPerineal-Ultraschalls fand sich eine echoarme, kugelige Struktur von $24 \times 26 \times 32 \mathrm{~mm}$ unmittelbar unterhalb der Symphyse zwischen distaler Urethra und dem Schambein. Diese Struktur war zuvor im 2-D-Ultraschall fälschlicherweise für die Symphyse in der Median-Ebene gehalten worden. Der Tumor konnte durch eine vaginale Inzision zwischen Meatus urethrae externus und Symphyse komplikationslos entfernt werden. Während des sonst unauffälligen postoperativen Verlaufs zeigte sich eine neuaufgetretene Belastungsharninkontinenz. Acht Wochen nach Primäroperation wurde die Belastungsharninkontinenz erfolgreich durch die Einlage einer retropubischen spannungsfreien Vaginalschlinge korrigiert. Nach weiteren 8 Wochen zeigte sich die Patientin bei subjektivem Wohlbefinden, kontinent und ohne Blasenentleerungsstörung bei unauffälligem Untersuchungsbefund. Den entscheidenden, wegweisenden Hinweis zur Diagnose und Ursache der Beschwerden erbrachte der 3-D-Ultraschall. Neben den hinreichend bekannten Vorteilen der Ultraschalldiagnostik, wie hoher Verfügbarkeit, Reproduzierbarkeit und Nebenwirkungsfreiheit, erweist sich der 3-D-Perineal-Ultraschall auch als hoch effektive Methode bei der Abklärung von Blasenentleerungsstörungen. 

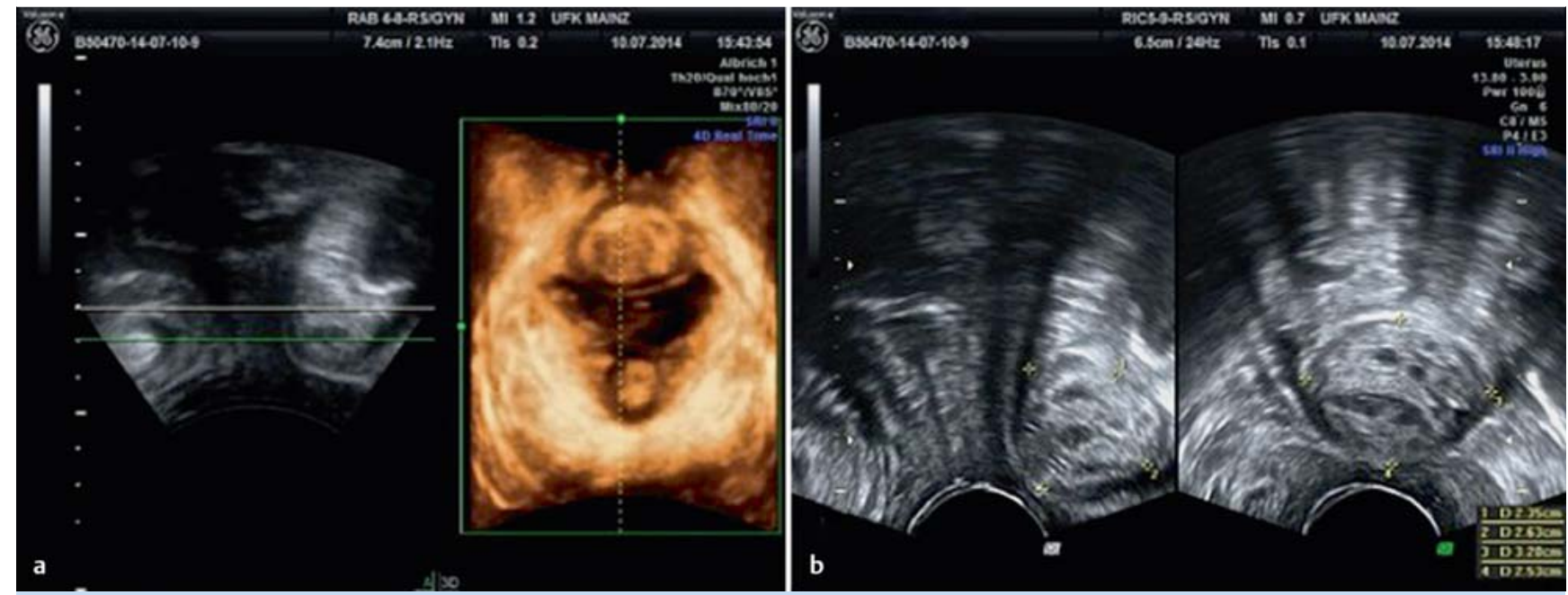

Fig. $\mathbf{1}$ a and $\mathbf{b}$ Perineal ultrasound. a Midsagittal plane and 3D rendered volume of coronal plane with subpubic tumor. $\mathbf{b}$ Midsagittal and transverse plane on 2D ultrasound with hypoechoic spherical structure.

\section{Introduction}

$\nabla$

Perineal ultrasound has become an indispensable tool in the evaluation of urogynecological patients with symptoms of pelvic floor dysfunction [1,2]. Due to its low cost, easy access and broad availability it has not only achieved high acceptance in urogynecology but also among urologists and coloproctologists [3]. It can provide static images of the anterior, middle and posterior compartments as well as showing the changes which occur during dynamic maneuvers such as pelvic floor muscle contraction and Valsalva. In contrast to $\mathrm{x}$-ray and magnetic resonance imaging (MRI), ultrasound allows alloplastic materials such as polypropylene slings and meshes to be visualized; this is particularly important as the use of such materials has increased dramatically in surgical urogynecology in recent years [4,5]. Ultrasound has therefore become the imaging method of choice in urogynecology. The introduction of 3D/4D technology has allowed urogynecologists to access the coronal plane in the female pelvic floor [6]. At the level of the plane of minimal hiatal dimensions we can identify the hyperechoic puborectal sling as the caudal part of the levator ani muscle complex. During Valsalva maneuver we can visualize and measure the genital hiatus framed by the pubic symphysis and the puborectal sling. Excessive distension of the hiatus, known as hiatal ballooning, is associated with signs and symptoms of pelvic organ prolapse [7]. Defects of the puborectal sling caused by vaginal delivery have also been shown to be associated with pelvic organ prolapse and the risk of recurrence after anterior repair [8]. Despite these clinically relevant capabilities and several scientific papers supporting its use, 3D perineal ultrasound is not yet widely used by clinicians.

\section{Case Report}

$\nabla$

A 73-year-old female patient presented with symptoms of voiding dysfunction and over-active bladder for approximately three years. She noted voiding dysfunction with a sensation of residual urine and voluntary bladder emptying only when in an upright position or leaning backwards. She reported symptoms of urgency, increased voiding frequency and rare episodes of urge in- continence, but no signs of urinary stress incontinence. The patient reported a micturition frequency of 12-13 times during the day, two episodes of nocturia, with an average daily fluid intake of about 1 liter and no use of incontinence pads. In addition she complained of recurrent urinary tract infections and chronic abdominal pain for three years. Antibiotic treatment for suspected cystitis offered no subjective benefit.

She had a medical history of two normal vaginal deliveries, histologically proven glomerulonephritis of unknown origin for several years and chronic bronchitis.

After several consultations with a general practitioner, her gynecologist and an urologist she was referred to our tertiary urogynecologic unit. Prior examinations had revealed no abnormality on palpation or 2D ultrasound, but significant residual urine and a reduced uroflow were present indicating bladder outlet obstruction.

On vaginal examination there was no sign of pelvic organ prolapse, no vaginal atrophy, discharge or bleeding. A clinical stress test was negative. Vaginal palpation revealed an intact bilateral levator ani muscle and poor muscle function on pelvic floor muscle contraction. Residual urine after spontaneous voiding was $300 \mathrm{ml}$ measured by catheterization, and urine dipstick analysis revealed no signs of infection or hematuria.

On routine 2D perineal ultrasound we found little movement of the bladder neck on maximal Valsalva maneuver, no sign of cystocele, rectocele or uterine prolapse.

On $3 \mathrm{D} / 4 \mathrm{D}$ ultrasound a $24 \times 26 \times 32 \mathrm{~mm}$ hypoechoic, oval structure was identified anterior to the urethrovesical junction (- Fig. 1). After this identification of a subpubic lesion in the coronal plane by 3D ultrasound, the previous 2D ultrasound was repeated.

The structure had been wrongly interpreted as the pubic symphysis in the midline on prior 2D ultrasound, due to the lesion's structure, shape and localization in the midline. This new knowledge of a subpubic hypoechoic, bone-like tumor explained its misinterpretation as the pubic symphysis on 2D perineal ultrasound.

With an unusual diagnosis of a subpubic tumor we recommended surgical removal by a vaginal route. In addition to the general surgical aspects patient was informed about possible 

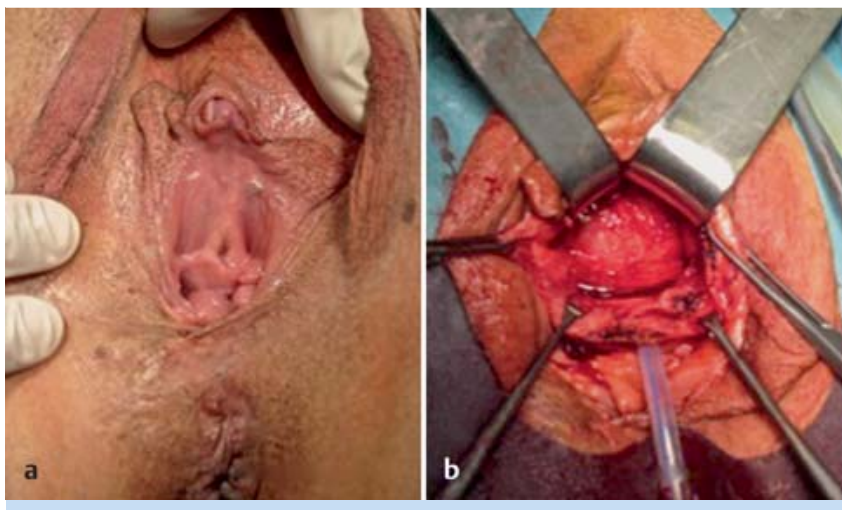

Fig. 2a and $\mathbf{b}$ a Preoperative situs. b Preparation of subpubic tumor after insertion of foley catheter and preurethral incision.

complications such as injury to the urethra or bladder and de-novo postoperative urinary stress incontinence in particular. As potential postoperative urinary stress incontinence is often caused by deterioration of the paravaginal support or affection of the nerve supply to the urethra, a two-stage anti-incontinence procedure after 6 to 8 weeks was agreed upon with the patient.

After an unremarkable cystourethroscopy and a horizontal incision ventral to the external urethral orifice, the solid structure was carefully dissected ( Fig. 2). Great attention was paid to preserving the urethral complex using a $4 \mathrm{~mm}$ Hegar dilator in the urethra. The tumor had a hard consistency, limited surrounding vascularization and was attached to the inferior rami of the pubic bone bilaterally ( Fig. 3). After hemostasis and wound closure with resorbable sutures, a 12 Charrière Foley catheter was inserted. The postoperative course was unremarkable, and the urinary catheter was removed on day 5 , resulting in spontaneous voiding without residual urine, but symptoms of urinary stress incontinence occurred. Histology revealed a $35 \mathrm{~mm}$ encapsulated, partly calcified pseudocyst with central necrosis and chronic inflammatory infiltration without signs of malignancy. On follow-up 6 weeks postoperatively, the patient reported wellbeing, no problems on voiding but the persistence of urinary incontinence on straining and exertion. She reported no pain, bleeding, discharge, dysuria or symptoms of over-active bladder. Pelvic examination and ultrasound revealed no abnormalities, problems with healing, hematoma or mass. Residual voiding volume on ultrasound was less than $20 \mathrm{ml}$. The clinical stress test was positive. Multichannel urodynamics revealed a normal filling phase without detrusor instability, a resting urethral closure pressure of $32.8 \mathrm{~cm} \mathrm{H}_{2} \mathrm{O}$ and a negative urethral stress profile.

As a result we recommended placement of a retropubic suburethral sling, which was inserted 8 weeks after initial removal of the subpubic tumor under analgosedation. The second postoperative course was also unremarkable; the patient was able to void without residual urine and was continent on discharge.

At the second follow-up our patient reported physical well-being and urinary continence, in particular she reported an absence of urinary stress incontinence, over-active bladder symptoms, voiding dysfunction or dysuria. Physical examination and ultrasound confirmed no residual urine volume, absence of residual mass or hematoma, and correct position of the midurethral tape. The clinical stress test was negative.

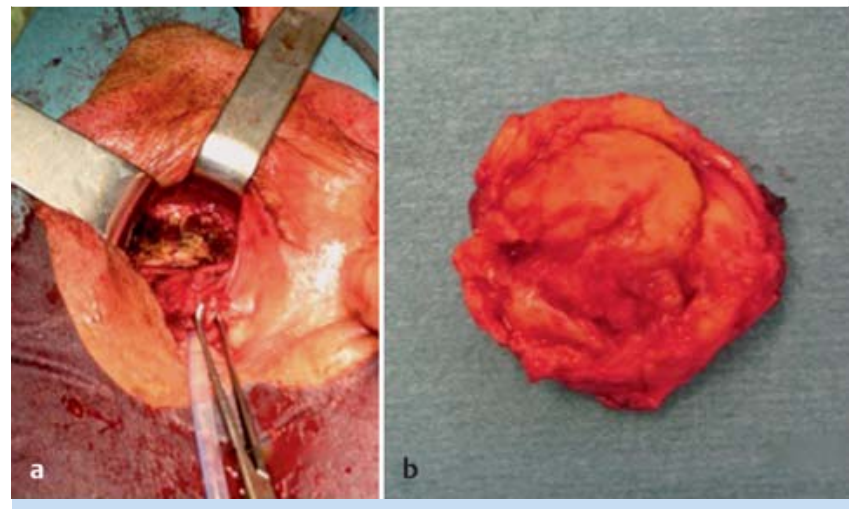

Fig. $\mathbf{3} \mathbf{a}$ and $\mathbf{b}$ a Situs after resection of subpubic tumor. $\mathbf{b}$ Subpubic tumor.

\section{Discussion}

$\nabla$

Bladder outlet obstruction in women can be categorized into iatrogenic or post-surgical (slings, meshes, hematoma), anatomic (cysts or myoma), and neurogenic [9]. As no surgical intervention had preceded the symptoms and there had been no neurologic incident, an anatomical reason for the bladder outlet obstruction was the most likely reason for the symptoms.

Management of female bladder outlet obstruction is often regarded as a challenge [10]. The usual workup consists of measurement of post-void residual volume, pressure flow studies, cystourethroscopy, endoscopic visualization and MRI [10-12]. Our patient had a significant residual volume of about $300 \mathrm{ml}$. A pressure flow study previously performed by an urologist had revealed reduced maximal flow. Cystourethroscopy and MRI were not performed due to the invasive nature of the procedure and the high costs, respectively.

Because of its good availability, low cost and non-invasiveness, perineal ultrasound is considered an indispensable part of urogynecology today.

Several anatomic structures such as the bladder, vagina, anorectum, levator muscle and pubic symphysis as well as synthetic materials such as slings, meshes and bulking agents can be visualized. Routine 2D imaging workup includes imaging all of the above-mentioned organs at rest, during pelvic floor muscle contraction, and at maximum Valsalva maneuver in the midsagittal plane. Visualization of structures can sometimes be difficult, and they may require identification during dynamic movement of the probe or the patient during a cine loop sequence.

Ultrasound can be used to diagnose incidental abnormalities of the lower genital tract such as Gartner's duct cysts or vaginal myoma $[13,14]$. However 2D ultrasound is limited by single plane imaging. Three-dimensional structures or warped shapes cannot be captured on a single plane.

Modern 3D ultrasound technology displays the coronal plane of the genital hiatus enabling urogynecologists to assess levator integrity and display abnormal hiatal distension. The "surface mode" in 3Dcan discriminate between different surfaces and thus contribute to detecting atypical anatomical structures. Warped structures like the puborectal sling of the levator ani muscle can also be visualized using semi-transparent volume rendering of 3D ultrasound data [15]. 
As illustrated in this case, the addition of 3D perineal ultrasound can help to interpret 2D ultrasound images and understand the pathophysiological conditions.

A subpubic cartilaginous cyst is an uncommon lesion that may present as a vulvar/vaginal mass or, rarely, with dysuria. This condition occurs predominantly in multiparous postmenopausal women and is believed to be secondary to degenerative changes in the fibrocartilaginous disc of the pubic symphysis. The midline location, the close proximity to the lower surface of the pubic symphysis, and the cystic nature are clues to the correct diagnosis [16].

If subpubic cartilaginous cyst is suspected, the tumor may be excised in symptomatic patients or observed in those who are asymptomatic. The standard of care for the management of these cysts has not yet been determined due to the rarity of this lesion [11].

Complete vaginal resection required separation of the urethra from the pubic symphysis, resulting in a loss of urethral suspension. This lack of pelvic support led to the development of de-novo urinary stress incontinence. Although the published literature mentions complete resolution of bladder outlet obstruction and the improvement of voiding function, no information on urinary continence is given $[11,17,18]$. In contrast to our vaginal approach, some of the cysts discussed in the literature were resected via an abdominal incision. The surgical route can affect urethral suspension and thus urinary continence. A vaginal incision, however, should affect urethral support less than dissection in the prevesical space using an abdominal route.

In the end, the successful treatment of urinary incontinence by inserting an alloplastic retropubic suburethral sling confirms the mechanism of suburethral slings as defined by Ulmsten's and Petros' integral theory of female urinary incontinence [19].

\section{Conclusion}

$\nabla$

There are several reports on paraurethral masses such as fibroids, Gartner's duct cysts and subpubic cartilaginous cysts. Postoperative voiding dysfunction can sometimes also occur after insertion of alloplastic materials such as suburethral slings or vaginal meshes for pelvic organ prolapse. Both tumors and synthetic polypropylene foreign bodies can be visualized on ultrasound. In some cases with unusual location of the urinary obstruction like the case presented here, 3D perineal ultrasound can be useful. This case confirms the indispensable role of 2D and 3D perineal ultrasound for routine urogynecological workup, and we recommend the use of 3D perineal ultrasound, especially in unusual cases of bladder outlet obstruction in urogynecology.

This is the first reported case of a subpubic cystic lesion diagnosed by 3D perineal ultrasound instead of expensive and resource-intensive MRI. We also describe the first case of successful restoration of clinical continence by a retropubic sling after urethral dissection and separation from the pubic symphysis.

\section{Conflict of Interest}

None.

\section{References}

1 Albrich S, Laterza R, Kölbl H. Stellenwert der 2D- und 3D-Perinealsonografie in der Urogynäkologie. Frauenheilkunde up2date 2011; 10 : 317-329

2 Tunn $R$, Albrich S, Beilecke $K$ et al. Interdisciplinary S2k guideline: sonography in urogynecology: short version - AWMF registry number: 015/055. Geburtsh Frauenheilk 2014; 74: 1093-1098

3 Albrich S, Bauer RM, Haberer E et al. [Importance of sonography in the diagnostics of functional disorders of the female pelvic floor]. Urologe A 2013; 52: 533-540

4 Dietz HP. The evolution of ultrasound in urogynecology. Ultrasound Obstet Gynecol 2010; 36: 655-657

5 Tunn R, Picot A, Marschke J et al. Sonomorphological evaluation of polypropylene mesh implants after vaginal mesh repair in women with cystocele or rectocele. Ultrasound Obstet Gynecol 2007; 29: 449-452

6 Dietz HP. Ultrasound imaging of the pelvic floor. Part II: three-dimensional or volume imaging. Ultrasound Obstet Gynecol 2004; 23: 615625

7 Dietz HP. Pelvic floor ultrasound in prolapse: what's in it for the surgeon? Int Urogynecol J 2011; 22: 1221-1232

8 Weemhoff $M$, Vergeldt TF, Notten $K$ et al. Avulsion of puborectalis muscle and other risk factors for cystocele recurrence: a 2-year follow-up study. Int Urogynecol J 2012; 23: 65-71

9 McCrery RJ, Appell RA. Bladder outlet obstruction in women: iatrogenic, anatomic, and neurogenic. Curr Urol Rep 2006; 7: 363-369

10 Klijer R, Bar K, Bialek W. Bladder outlet obstruction in women: difficulties in the diagnosis. Urol Int 2004; 73: 6-10

11 Ghareeb GM, Grabemeyer H, Dietrich E et al. Subpubic cartilaginous cyst presenting as acute urinary retention: a report and review of the literature. Female Pelvic Med Reconstr Surg 2013; 19: 58-60

12 Groutz A, Blaivas JG, Chaikin DC. Bladder outlet obstruction in women: definition and characteristics. Neurourol Urodyn 2000; 19: 213-220

13 Voigt $R$, Stech $D$, Pirlich $W$. [Acute urine retention in a large myoma of the perivesical connective tissue]. Zentralbl Gynakol 1987; 109: 598603

14 Dietz HP. Ultrasound imaging of the pelvic floor. Part I: two-dimensional aspects. Ultrasound Obstet Gynecol 2004; 23: 80-92

15 Kruger JA, Heap SW, Murphy BA et al. How best to measure the levator hiatus: evidence for the non-Euclidean nature of the 'plane of minimal dimensions'. Ultrasound Obstet Gynecol 2010; 36: 755-758

16 Vanhoenacker FM, Govaerts J, Bernard P et al. Subpubic cartilaginous cyst: a rare cause of dysuria. JBR-BTR 2013; 96: 295-297

17 Alguacil-Garcia A, Littman CD. Subpubic cartilaginous cyst: report of two cases. Am J Surg Pathol 1996; 20: 975-979

18 Farag F, van der Geest I, Hulsbergen-van de Kaa C et al. Subpubic cartilaginous pseudocyst: orthopedic feature with urological consequences. Case Rep Urol 2014; 2014: 176089

19 Petros PE, Ulmsten UI. An integral theory of female urinary incontinence. Experimental and clinical considerations. Acta Obstet Gynecol Scand Suppl 1990; 153: 7-31 